\title{
Application of new insoluble dietary fibres from triticale as supplement in yoghurt - effects on physico-chemical, rheological and quality properties
}

\author{
Jelena Miocinovic, ${ }^{a^{*}}$ Nikola Tomic, ${ }^{b}$ Biljana Dojnov, ${ }^{c}$ Igor Tomasevic, ${ }^{a}$ \\ Sanja Stojanovic, ${ }^{d}$ lija Djekic ${ }^{b} \odot$ and Zoran Vujcic ${ }^{d}$
}

\begin{abstract}
BACKGROUND: The need to increase the daily intake of dietary fibres opens a new chapter in the research of functional foods enriched with fibres. The potential application of an innovative product - insoluble dietary fibres from triticale in yoghurts - was deployed by characterising their food application and evaluating physico-chemical, rheological and sensory properties and was the aim of this research.

RESULTS: Detailed characterisations of these fibres are presented for the first time and showed very good hydration properties, optimal pH (slightly acidic), optimal chemical composition, high antioxidant capacity which was proven by phenolics contents. Besides, these fibres showed negligible calorific value, with no phytates and high antioxidant capacity, mainly from ferulic acid. Therefore they could be successfully added to yoghurt. Enrichment of yoghurt having different milk fat content (1.5 and $2.8 \%$ $\mathrm{w} / \mathrm{w})$ with triticale insoluble fibre $(1.5 \%$ and $3.0 \% \mathrm{w} / \mathrm{w})$ significantly influenced the syneresis level, its apparent viscosity, yield stress and thixotropic behaviour. The overall sensory quality scores indicated that yoghurt enriched with $1.5 \%$ triticale insoluble fibres was recognised as 'excellent' and had enhanced antioxidant activity.
\end{abstract}

CONCLUSIONS: Insoluble triticale fibre could therefore be used as a supplement to produce functional yoghurt. (c) 2017 Society of Chemical Industry

Keywords: yoghurt; triticale; insoluble dietary fibre; rheology; antioxidant activity

\section{INTRODUCTION}

The International Life Science Institute established that 'a food product can be considered as functional if it has satisfactorily been proved that it produces a beneficial effect on one or more physiological functions, besides its conventional nutritional effects, being this relevant for improving the human health and/or reducing the risk of suffering certain diseases'. ${ }^{1}$ Insoluble dietary fibre (IDF) is known to increase stool weight and decrease colonic transit time, ${ }^{2}$ which ensures prevention of colonic diverticulosis and constipation. ${ }^{3}$ The second important benefit of IDF is the antioxidant capacity that comes from phenolics and may contribute to the health benefits. ${ }^{4}$ Despite the proven healthful influence of IDF on chronic disease risk reduction, the average worldwide ingestion of this component is considered as low. There is pressing need for increasing of daily intake of IDF.

Triticale IDF (IDFT) is an innovative product ${ }^{5}$ and can be considered as a good candidate for the addition in functional foods. IDFT is a low-calorie, non-allergenic dietary fibre obtained by innovative technology from triticale ( $\times$ Triticosecale, Wittmak), a hybrid of wheat (Triticum sp.) and rye (Secale sp.). Triticale contains high levels of nutritionally beneficial compounds such as phenolic acids and IDF. ${ }^{6,7}$ It is cultivated in more than 30 countries $^{8}$ and has many benefits compared to other crops, but is insufficiently utilised as yet. ${ }^{9}$ Triticale is little represented in the human diet. ${ }^{10}$ Usage of IDFT in some dietary products could increase the contribution of triticale in human diets, daily intake of IDF and cultivation of this interesting grain.

Fermented dairy products already have a positive health image due to the beneficial action of their viable bacteria. ${ }^{11}$ Yoghurt is a very popular fermented dairy product and represents a good base for development of enriched food in order to improve its

\footnotetext{
Correspondence to: J Miocinovic, Department of Animal Source Food Technology, University of Belgrade - Faculty of Agriculture, Belgrade, Republic of Serbia.E-mail:jmiocin@agrif.bg.ac.rs

a Department of Animal Source Food Technology, University of Belgrade - Faculty of Agriculture, Belgrade, Republic of Serbia

b Food Safety and Quality Management Department, University of Belgrade - Faculty of Agriculture, Belgrade, Republic of Serbia

c Department of Chemistry, Institute of Chemistry, Technology and Metallurgy, Belgrade, Republic of Serbia

d Department of Biochemistry, University of Belgrade - Faculty of Chemistry,
} Belgrade, Republic of Serbia 
nutritional value and health benefits. In this sense it has been shown that it is possible to enrich the yoghurt with IDF from a number of sources - soy, rice, oat, corn and sugar beet. ${ }^{12}$ Use of new sources of fibre is recommended for several reasons: (1) to develop novel food considering technological and physiological functionality of dietary fibre depending on its sources and chemical composition; (2) to contribute to the social and economic development of local producers by successfully applying the fibres of native plants in food; and (3) to promote higher acceptability of fibre-rich products, using local and traditionally consumed plants as sources of dietary fibre. ${ }^{13}$ The main criteria for the acceptability of fibre-enriched foods are: good processing behaviour, good stability and appearance and satisfactory sensory properties. ${ }^{14}$

The aim of this study was to investigate the potential application of IDFT in yoghurt production. Hence, the objective of the present work is two-fold: (1) to characterise IDFT and identify possibilities for food application and (2) to evaluate and compare the composition, syneresis, and rheological behaviour, textural and sensory properties of stirred yoghurt having different fat and insoluble fibre contents. Results should provide important insights in the potential commercialisation of this fibre as a novel functional component of dairy products.

\section{MATERIALS AND METHODS \\ Characterisation of triticale fibres}

IDFT was obtained by innovative environmental friendly technology 5 based on auto-hydrolytic properties of triticale. Triticale has its own $\alpha$-amylases which can hydrolyse all starch present in grain, which is already used for bioethanol production ${ }^{15}$ and for fungal amylase production. ${ }^{16}$ This characteristic was used in the IDFT production technology, too. IDFT are without taste and odour, low-calorie and non-allergenic.

Elemental microanalyses were performed on a elemental analyser (LecoCHNS-932; LECO Corporation, St. Joseph, MI, USA), by the standard micromethod. Elemental concentrations of trace elements were determinate by inductively coupled plasma-atomic emission spectroscopy (ICP-AES).

Hydration properties of dietary fibre are described by three commonly used characteristics: the swelling capacity (SC), water and fat, water retention capacity (WRC), and fat/oil retention capacity (ORC). These characteristics were determined at $25^{\circ} \mathrm{C}$ according to standardised procedures. ${ }^{17}$

Specific hydration properties of IDFT were determinate in accordance with the requirements of the yoghurt preparation, because it was added to yoghurt during the preparation process. In this way, IDFT suffered temperature changes following the yoghurt process, and it is known that the hydration properties of the fibres depend on the temperature and the incubation time. We have also introduced a new specific feature of the fibre - milk retention capacity (MRC) because IDFT comes into contact with milk during the yoghurt process, and milk and water are not the same, and the same behaviour of fibres in terms of swelling and retention is not expected. WRC, MRC and ORC were determinate after incubation and centrifugation ( $1 \mathrm{~min}$ on $14000 \times \mathrm{g}$ ) of IDFT in water, milk and butter respectively on $90^{\circ} \mathrm{C}$ for $30 \mathrm{~min}$, than cooled on $45^{\circ} \mathrm{C}$ for $4 \mathrm{~h}$.

The $\mathrm{pH}$ of IDFT was determinate in $10 \%(\mathrm{w} / \mathrm{v})$ IDFT suspension. The acidity was determined by titration with $\mathrm{NaOH}\left(0.1 \mathrm{~mol} \mathrm{~L}^{-1}\right)$ to $\mathrm{pH} 8.1$, and the results were expressed as g citric acid $100 \mathrm{~mL}^{-1}$ sample. ${ }^{18}$

Moisture content analysis was done by determining content of water by the drying method. The ash content analysis was performed by the method of incineration according to local standardised analysis methods for the food industry.

IDFT was analysed for contents of proteins in buffer extracts according to the Bradford method, ${ }^{19}$ residual sugars were detected by the 3,5-dinitrosalicylic acid (DNS) method, ${ }^{20}$ while eventual non-hydrolysed starch content was determinate using iodine reagents. ${ }^{21}$ The phytate content in IDFT was determined according to the colour method for phytase activity. ${ }^{22}$

Phenolic contents of IDFT were determinate in three extracts. Free and bound phenolics were extracted according to the procedures used for phenolics analysis in triticale bran. ${ }^{7}$ Total phenolic content was determinate by the Folin-Ciocalteu method, ${ }^{23}$ expressed as ferulic acid equivalents $\left(\mathrm{mg} 100 \mathrm{~g}^{-1}\right)$ based on triplicate measurements.

Individual phenolics concentrations ( $p$-coumaric, ferulic, vanillic and syringic acids) were analysed by HPLC-DAD (Thermo Dionex Ultimate 3000 HPLC system, Thermo Dionex Cromeleon 7 software; Dionex, Sunnyvale, CA, USA). The separation of phenolics was accomplished on a reversed-phase Hypersil GOLD aQ-C18 column $(150 \times 3.0 \mathrm{~mm})$. The mobile phases were A (TFA) and B (acetonitrile) at a flow rate of $0.5 \mathrm{~mL} \mathrm{~min}^{-1}$, the injection volume was 20 $\mu \mathrm{L}$ for each sample. A gradient system was used as follows: 0 min $5 \%$ B, $0-29$ min gradient $5-60 \%$ B; 30-37 min 5\% B, 37-50 min 5\% B. Elution of compounds of interest was monitored at a wavelength of $280 \mathrm{~nm}$. For phenolic acids content, ferulic acid, p-coumaric, syring and vanillic acids in methanol were used as the standards and peaks were quantified based on areas and calculated as equivalents ( $\mu \mathrm{g} \mathrm{g}^{-1}$ IDFT).

\section{Production of yoghurt}

Pasteurised and homogenised milk with different fat content (1.5

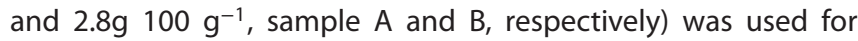
yoghurt preparation. Yoghurts were prepared in three variants: control samples without fibre (A0 and B0), with 1.5\% (1.5 g IDFT $100 \mathrm{~g}^{-1}$ yoghurt, $\mathrm{A} 1$ and $\mathrm{B} 1$ ) and $3 \%\left(3 \mathrm{~g} \mathrm{IDFT} 100 \mathrm{~g}^{-1}, \mathrm{~A} 2\right.$ and B2). Fibres were added before milk heat treatment. Starter culture ('Yoflex 812'; Chr Hansen, Nieuwegein, Netherlands) was added in the amount of $0.02 \%(\mathrm{w} / \mathrm{w})$. Fermentation was set at $43^{\circ} \mathrm{C}$ until $\mathrm{pH}$ 4.6 was reached. Yoghurt samples were mixed and cooled during $24 \mathrm{~h}$ at temperature of $4-7^{\circ} \mathrm{C}$ and analysed.

\section{Characterisation of the yoghurt}

The total solids, fat and proteins content in the yoghurts were determined by standard methods. ${ }^{24}$

Rheological properties of stirred yoghurt samples were performed at $5^{\circ} \mathrm{C}$ on a Rheometer (Kinexus Pro+; Malvern Instruments, Malvern, UK) with the four-blade vane as a tool. Data processing was performed using a software package, (Kinexus Version 1.60; Malvern Instruments).

Flow behaviour of yoghurt samples was characterised by a thixotropic test. Shear stress was recorded at increasing and decreasing shear rates from 0 to $40 \mathrm{~s}^{-1}$ within $50 \mathrm{~s}$ (upward and downward flow curves). Thixotropic behaviour of the samples was investigated by hysteresis loop area $\left(\mathrm{A}, \mathrm{Pa} \mathrm{s}^{-1}\right)$ which was determined as difference in area under upward and downward flow curves by a software (Origin 8.0; OriginLab Corp., Northampton, MA, USA). Apparent viscosity $\left(\eta_{\text {app }}\right)$ was calculated at $10 \mathrm{~s}^{-1}$ of shear rate.

A dynamic oscillation test was subsequently conducted following the flow behaviour assessment to characterise the visco-elastic properties of yoghurt samples. 
Strain sweeps were performed $(0.001-500 \%)$ to determine the linear visco-elastic range (LVR) of samples at a constant frequency of $1 \mathrm{~Hz}$. The yield stress value were calculated from the cross-over $\left(G^{\prime \prime}=G^{\prime \prime}\right)$ point outside of the LVE. ${ }^{25}$

Syneresis properties were analysed by measurement of clear supernatant obtained after centrifugation ( $222 \times \mathrm{g}$ for $10 \mathrm{~min}$ ) of 40 $g$ of yoghurts at $4 \pm 1^{\circ} \mathrm{C}^{26}$.

Texture properties of yoghurts such as firmness, consistency, cohesiveness and index of viscosity, were determined by texture analyser equipment (TA.HD; Stable Micro Systems, Godalming, UK) through a single compression test, using a back-extrusion cell (A/BE) disc and an extension bar, using $5 \mathrm{~kg}$ load cell at $5^{\circ} \mathrm{C}$. Tests were carried out in a standard sized back-extrusion container (50 $\mathrm{mm}$ diameter) approximately $75 \%$ full immediately after removal from storage.

Sensory quality rating was conducted by a sensory panel that consisted of 10 members experienced in judging the quality of dairy. Quality grading was performed using a five-level quality scoring method. Overall sensory quality was assessed by evaluating four initially selected characteristics: appearance, odour, oral texture and flavour that were assigned appropriate values of coefficients of importance: 3, 2,9 and 6, respectively. In order to calculate the overall quality score, individual scores given to the selected sensory characteristics were first multiplied by the corresponding coefficients of importance, and then the sum of corrected score-values was divided by the sum of coefficients of importance.

All experimental samples were evaluated by the sensory panel in three replicates after both 2 and 9 days of storage at $4^{\circ} \mathrm{C}$ after the yoghurt was manufactured.

\section{Antioxidant capacity of IDFT and yoghurt enriched with IDFT}

Antioxidant capacity of yoghurt, IDFT and yoghurt enriched with IDFT were determinate. For analysis, yoghurt with $2.8 \%$ milk fat and $1.5 \%$ IDFT was chosen as the best rated showed in the previous analysis.

\section{ABTS radical scavenging assay}

ABTS radical cation $\left(\mathrm{ABTS}^{\bullet+}\right.$ ) was produced by reacting $7 \mathrm{mmol}$ $\mathrm{L}^{-1}$ ABTS stock solution with $2.45 \mathrm{mmol} \mathrm{L}^{-1}$ ammonium persulfate and allowing the mixture to stand in the dark at room temperature for $12-16 \mathrm{~h}$ before use. The ABTS ${ }^{\bullet+}$ solution was diluted with methanol to an absorbance of $0.70 \pm 0.02$ at $700 \mathrm{~nm}$. Diluted $\mathrm{ABTS}^{\bullet+}$ solution $(3.9 \mathrm{~mL}$ ) were mixed with $100 \mu \mathrm{L}$ of sample or vitamin C standard and reaction (decrease in absorbance) were monitored during $15 \mathrm{~min}$. Vitamin $\mathrm{C}$ solutions of known concentrations were used for calibration. Antioxidant capacities were expressed as $\mu$ mol vitamin $\mathrm{C} \mathrm{g}^{-1}$ of sample. ABTS radical scavenging assay was determined also in all three phenolics fractions: extracts of IDFT bound, free and water dissolved).

\section{Radical scavenging activity assay}

Radical scavenging activity (RSA) was measured according to the Brand-Williams method. ${ }^{27}$ An aliquot of sample $(200 \mu \mathrm{L})$ was mixed with $2.9 \mathrm{~mL}$ of $60 \mu \mathrm{mol} \mathrm{L}{ }^{-1}$ 2,2-diphenyl-1-picrylhydrazyl (DPPH) in methanol solution and vortexed. Reaction was carried out in the dark for $30 \mathrm{~min}$. Antioxidant activity was expressed as percentage inhibition of the DPPH radical and was determined by the equation:

$$
\text { RSA }(\%)=\frac{A_{\text {control }}-A_{\text {sample }}}{A_{\text {control }}} \times 100
$$

where $A_{\text {control }}$ and $A_{\text {sample }}$ are antioxidant activity without and with Triticale fibers, respectively.

\section{Determination of total phenolic content}

Total phenolic content (TPC) was determined by the Folin-Ciocalteu method, ${ }^{23}$ expressed as ferulic acid equivalents

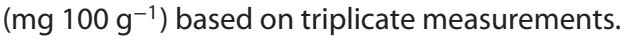

\section{Statistical analysis}

Results of the effects of fat and fibre content on the yoghurts properties were analysed using analysis of variance (ANOVA). The mean comparisons of the parameters were performed with post-hoc LSD test at $P<0.05$.

The sensory data were first analysed separately by three-way ANOVA that included 'samples' as a fixed factor, and 'assessors' and 'replications' as random factors. The model included main effects and all two-way interactions. The Tukey HSD test was used to separate the mean quality scores. In the second iteration, original sensory data were subjected to four-way ANOVA that included 'milk fat content', 'fibre content', and 'storage' as fixed factors and 'assessors' as a random factor. The model included main effects, all two-way interactions, and the fixed factors three-way interaction. The level of statistical significance was set at 0.01 .

\section{RESULTS AND DISCUSSION Characterisation of IDFT}

Chemical analysis of IDFT, Table 1 (columns A and B), was intended to show the amounts of digestible components of IDFT, proteins, starch and sugar. All examined components were present in traces comparing to analogue cereal IDF. ${ }^{28}$ These results confirm negligible caloric value and hypoallergenic properties of IDFT. Addition of IDFT in yoghurt will not increase caloric value. This is important for functional foods enriched with IDF that could be part of a menu of people on restrictive diets.

There were no phytates in IDFT [Table 1 (column A)]. Consumption of food enriched by IDFT contributes to meeting the daily intake of IDF without negative consequences that arise by entering cereal or whole grains. Phytates from cereals associate with IDF, complexed with $\mathrm{Zn}^{2+}, \mathrm{Ca}^{2+}$ and $\mathrm{Fe}^{2+}$ in the digestive tract disables their resorption. ${ }^{29}$

Elemental microanalysis of IDF is not a common analysis in the literature. Usually it includes only one or a few elements of interest. ${ }^{30}$ It is known that triticale is rich in major mineral elements $(\mathrm{K}, \mathrm{P}, \mathrm{Mg}$ ) and nutritionally important minor elements ( $\mathrm{Na}, \mathrm{Mn}, \mathrm{Fe}$, $\mathrm{Cu}, \mathrm{Zn}) .{ }^{31}$ We showed that IDFT retains essential elements $(\mathrm{Na}, \mathrm{K}$, $\mathrm{Fe}, \mathrm{Mn}, \mathrm{Mg}, \mathrm{Ca}, \mathrm{Co}$ ) from triticale, while there were no heavy metals [Table 1 (column C)].

Hydration properties of IDF contribute to stabilisation of the structure of foods (dispersions, emulsions and foams) by modifying the rheological properties of the continuous phase and influence food texture. Capacity for fat absorption enhances their retention of fat that is normally lost during cooking, which could be beneficial for flavour retention and to increase the technological yield. ${ }^{14}$ SC, WRC and ORC of IDFT, presented in Table 2, are in the range or higher than analoguous IDF from cereals. ${ }^{28,32}$

Adding of IDF in food usually requires adjusting recipes for product preparation and/or special pretreatment of IDF because of their hydration properties. ${ }^{33}$ In this respect we implemented the specific characterisation of IDFT additionally, included the WRC, ORC and MRC on temperature and time corresponding to yoghurt preparation process. The specific WRC and ORC were higher than standard WRC and ORC at room temperature (Table 2). It implies that usage of IDFT in yoghurt was a good target choice. 


\begin{tabular}{|lccc|}
\hline \multicolumn{4}{|c|}{ Table 1. Chemical analysis of triticale insoluble dietary fibre (IDFT $)^{1}$} \\
A & $\begin{array}{c}\text { Amount } \\
\left(\mathrm{mg} \mathrm{g}^{-1} \mathrm{IDFT}\right)\end{array}$ & $\mathrm{B}$ & Amount (\%) \\
\hline Proteins & $1.99 \pm 0.08$ & Nitrogen & $2.41 \pm 0.11$ \\
Reduction sugars & $2.32 \pm 0.11$ & Carbon & $45.65 \pm 1.95$ \\
Starch & $0.84 \pm 0.03$ & Hydrogen & $7.19 \pm 0.26$ \\
Phytates & $0.00 \pm 0.0$ & Sumpor & $0.34 \pm 0.01$ \\
$\mathrm{C}$ & Concentration & $\mathrm{C}$ & Concentration \\
& $\left(\mu \mathrm{g} \mathrm{g}^{-1}\right.$ fibre $)$ & & $\left(\mu \mathrm{g} \mathrm{g}^{-1}\right.$ fibre) \\
$\mathrm{Al}$ & 8.36 & $\mathrm{Li}$ & 0.02 \\
$\mathrm{~B}$ & 3.81 & $\mathrm{Mg}$ & 3538.18 \\
$\mathrm{Ca}$ & 6398.17 & $\mathrm{Mn}$ & 128.68 \\
$\mathrm{Cd}$ & 0.05 & $\mathrm{Na}$ & 345.66 \\
$\mathrm{Co}$ & 0.04 & $\mathrm{Ni}$ & 0.27 \\
$\mathrm{Cr}$ & 0.14 & $\mathrm{~Pb}$ & 0.00 \\
$\mathrm{Cu}$ & 7.19 & $\mathrm{Sr}$ & 3.26 \\
$\mathrm{Fe}$ & 134.67 & $\mathrm{Zn}$ & 76.97 \\
$\mathrm{~K}$ & 1040.35 & & \\
\hline
\end{tabular}

All experiments were carried out in triplicate. Values represent means of three replicated trials \pm standard deviations. Standard deviations were less than $5 \%$.

Column A lists the content of proteins, reduction sugars, starch and phytates expressed as quantity in mg per $\mathrm{g}$ of IDFT.

Column B gives results for the microanalysis of IDFT.

Column C shows results for the ICP analysis of IDFT.

Higher WRC, ORC and MRC indicate that IDFT could contribute to higher stability and to retention of original taste of yoghurt. ${ }^{33}$ It also implies that specific characterisation of IDF could be a good indicator in terms of behaviour prediction of IDF during food preparation processes.

Table 2 confirms that $\mathrm{pH}$, moisture and ash content were within legal reference values. The slightly acidic pH of IDFT fits well with the yoghurt preparation process which requires a slightly acid environment. High acidity of IDFT, compared with other dietary fibre, ${ }^{18}$ will contribute to the buffering capacity during yoghurt preparation process.

Antioxidant dietary fibre can be defined as a product containing significant amounts of natural antioxidants associated with the fibre matrix. ${ }^{34}$ IDFT has a very high antioxidant capacity, measurement in every phenolic fraction (Table 2 ) and hence may be considered as a good candidate for antioxidant dietary fibre.

Comparisons of antioxidant capacities of IDF from cereals are very difficult due to the usage of different antioxidant tests and different expression pattern of results in literature. Nevertheless, analogue triticale fractions of phenolics showed similar relation in values of antioxidant capacity between bound and free phenolics. $^{7}$

The phenolics content of IDFT with HPLC analysis of individual components IDFT retained about $30 \%$ of total polyphenols relative to triticale bran. Most of phenolics were bound in IDFT, as shown in triticale bran too. ${ }^{7}$ In triticale the predominant phenolic acid is ferulic acid as well as in other cereals, where it serves as a bridge between lignin and polysaccharides (arabinoxylans) via ether and ester bonds. ${ }^{35}$ Other most common phenolic acids in triticale are p-coumaric and vanillin. ${ }^{7}$ From results reported here it can be concluded that IDFT retained about $30 \%$ of ferulic acid and $100 \%$ of $p$-coumaric and vanillic acids from triticale as started material. Syringic acid was completely lost in the process of obtaining IDFT from triticale. ${ }^{7}$
The characteristics of IDFT imply that this innovative product could be successfully added to a commonly used food without significantly changing the purpose and taste of them and at the same time making them functional foods.

\section{Characterisation of the yoghurt}

Chemical composition and syneresis of yoghurts

Fermentation for all samples lasted about $4 \mathrm{~h}$ and $\mathrm{pH}$ values were not significantly influenced by addition of IDFT one day after production (data not presented). The yoghurts dry matter contents were influenced by different fat and IDFT contents while the significant influence $(P<0.05)$ on the protein content was not found (Table 3 ) which is important from allergenic point of view.

The fat and IDFT contents significantly influences $(P<0.05)$ on the syneresis level. As expected, the higher level of syneresis was found in yoghurts with lower fat content. Low-fat products due to defects are usually produced with the addition of some ingredients in order to improve the textural properties. ${ }^{36}$ The presence of insoluble fibre, such as IDFT, which does not incorporate within protein network, contributes to a higher level of syneresis. Zare et al. ${ }^{37}$ found that syneresis in yoghurts supplemented with $1-2 \%$ lentil flour was significantly higher than in all other samples. Opposite to that, other authors ${ }^{38}$ showed that whey separation is reduced in yoghurts made with passion fruit fibres probably due to the pectin present in this kind of fibre. Maximum concentration of triticale bran which could be acceptable for consumer perspective and stability of product is $4 \%{ }^{6}$ which was confirmed for IDFT in our research.

\section{Rheological properties of yoghurts}

Yoghurts exhibit a variety of non-newtonian characteristics, such as visco-elasticity, time-dependency, yield stress and shear-thinning behaviour. ${ }^{39}$

A decrease in apparent viscosity $\left(\eta_{\mathrm{app}}\right)$ with increasing shear rate was found in all yoghurts indicating shear thinning behaviour (Fig. 1). Two-factorial ANOVA showed that both factors, fat and IDFT, significantly influenced $\eta_{\text {app }}$ value. The higher fat content in yoghurt contributed to the higher apparent viscosity, while addition of IDFT resulted in the decreasing of $\eta_{\text {app }}(P<0.05)$. It has been confirmed that the type of fibre influences the apparent viscosity of yoghurts. ${ }^{40}$ The structure of the initial gel network and the breakdown process used to convert the gel into the stirred yoghurt affected the physical and sensory properties of products. Weak gels due to poor protein-protein interactions resulted in decreased stiffness of initial gels. This also contributed to decreased $\eta_{\text {app }}$ and sensory properties of stirred yoghurts. The process parameters, such as preheating temperature and incubation temperature highly influence on the initial gel properties as well as on the final product. ${ }^{39}$

Yoghurts show thixotropic behaviour in which a sample is sheared at increasing and then at decreasing shear rates, the hysteresis area between the curves is observed (Fig. 2). Hysteresis loop area $\left(\mathrm{A}, \mathrm{Pa} \mathrm{s}^{-1}\right)$ presents the energy that is needed to destroy the structure of material. Our data showed that fat content significantly influenced on the hysteresis loop area $(P<0.05)$, while the effect of IDFT addition was not found. Yoghurts with the higher fat content require the higher energy to break down the structure.

The significant influence of fat and IDFT content on the yield stress was found $(P<0.05)$ (Table 3 ). The yield stress value indicates the difficulty in breaking strands representing fracture properties of gel depends on the number of bonds per cross section of the 


\begin{tabular}{|c|c|c|c|c|}
\hline \multicolumn{2}{|l|}{ Hydration property of IDFT } & \multirow{2}{*}{$\begin{array}{r}\text { Value } \\
5.3\end{array}$} & \multicolumn{2}{|r|}{ Reference value } \\
\hline \multirow[t]{2}{*}{ Swelling capacity } & Water & & \multicolumn{2}{|r|}{ - } \\
\hline & Oil & 2.0 & \multicolumn{2}{|r|}{ - } \\
\hline \multirow[t]{2}{*}{ Standard characterisation } & WRC & 4.7 & \multicolumn{2}{|r|}{ - } \\
\hline & ORC & 1.6 & \multicolumn{2}{|r|}{-} \\
\hline \multirow[t]{3}{*}{ Specific characterisation } & WRC & 5.3 & \multicolumn{2}{|r|}{-} \\
\hline & ORC & 2.5 & \multicolumn{2}{|r|}{ - } \\
\hline & MRC & 5.5 & \multicolumn{2}{|r|}{-} \\
\hline \multicolumn{2}{|l|}{ Acidity $^{*}$} & 0.5 & \multicolumn{2}{|r|}{ - } \\
\hline \multicolumn{2}{|l|}{$\mathrm{pH}$} & 5.4 & \multicolumn{2}{|r|}{$5.0-8.0$} \\
\hline \multicolumn{2}{|l|}{ Moisture (\%) } & 4.5 & \multicolumn{2}{|r|}{$\max 8.0$} \\
\hline \multicolumn{2}{|l|}{ Ash (\%) } & 2.5 & \multicolumn{2}{|r|}{$\max 3.0$} \\
\hline \multicolumn{2}{|c|}{ Antioxidant properties of IDFT } & Bound phenols & Free phenols & Phenols dissolved in the aqueous phase \\
\hline \multicolumn{2}{|c|}{ ABTS ( $\mu$ mol vitamin $\mathrm{Cg}^{-1}$ sample) } & 15856.16 & 57.12 & 1842.47 \\
\hline \multicolumn{2}{|c|}{ Total phenolic content (mg $100 \mathrm{~g}^{-1}$ IDFT) } & 99.0 & 5.0 & 11.3 \\
\hline \multicolumn{2}{|c|}{$p$-Cumaric acid $\left(\mu \mathrm{g} \mathrm{g}^{-1}\right.$ IDFT) } & 11.1 & 1.2 & 0.086 \\
\hline \multicolumn{2}{|c|}{ Ferulic acid $\left(\mu \mathrm{g} \mathrm{g}^{-1}\right.$ IDFT) } & 30.1 & 0.44 & 0.15 \\
\hline \multicolumn{2}{|l|}{ Vanillic acid ( $\mu \mathrm{g} \mathrm{g}^{-1}$ IDFT) } & 1.5 & 0.0 & 0.0 \\
\hline \multicolumn{2}{|l|}{ Syringic acid $\left(\mu \mathrm{g} \mathrm{g}^{-1}\right.$ IDFT) } & 0.0 & 0.0 & 0.0 \\
\hline
\end{tabular}

\begin{tabular}{|c|c|c|c|c|c|c|}
\hline $\begin{array}{l}\text { Yoghurt } \\
\text { sample }\end{array}$ & $\begin{array}{c}\text { Dry } \\
\text { matter (\%) }\end{array}$ & $\begin{array}{l}\text { Proteins } \\
\text { (\%) }\end{array}$ & 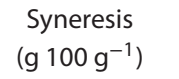 & $\begin{array}{c}A_{\text {up }}-A_{\text {down }} \\
\left(\mathrm{Pa} \mathrm{s}^{-1}\right)^{\dagger}\end{array}$ & $\begin{array}{c}\text { Yield } \\
\text { stress (Pa) }\end{array}$ & $\begin{array}{l}\text { App. viscosity } \\
\text { at } 10 \mathrm{~s}^{-1} \text { (Pa s) }\end{array}$ \\
\hline AO & $10.49 \pm 0.32^{\mathrm{a}}$ & $3.14 \pm 0.12^{\mathrm{a}}$ & $12.44 \pm 1.30^{\mathrm{a}}$ & $287^{a}$ & $9.54 \pm 2.45^{\mathrm{ac}}$ & $2.90 \pm 0.14^{\mathrm{a}}$ \\
\hline $\mathrm{A} 1$ & $12.29 \pm 0.21^{b}$ & $3.41 \pm 0.18^{a}$ & $22.04 \pm 0.75^{b}$ & $275^{\mathrm{a}}$ & $4.79 \pm 0.67^{b}$ & $2.62 \pm 0.16^{a}$ \\
\hline $\mathrm{A} 2$ & $13.15 \pm 0.44^{c}$ & $3.61 \pm 0.20^{a}$ & $29.54 \pm 3.34^{c}$ & $134^{\mathrm{a}}$ & $2.74 \pm 1.14^{b}$ & $1.76 \pm 0.49^{b}$ \\
\hline BO & $12.01 \pm 0.08^{b d}$ & $3.28 \pm 0.12^{\mathrm{a}}$ & $6.49 \pm 0.57^{d}$ & $595^{\mathrm{b}}$ & $11.84 \pm 1.63^{\mathrm{a}}$ & $5.28 \pm 0.25^{c}$ \\
\hline B1 & $13.23 \pm 0.17^{c e}$ & $3.42 \pm 0.11^{\mathrm{a}}$ & $14.49 \pm 0.32^{\mathrm{e}}$ & $456^{\mathrm{b}}$ & $8.10 \pm 1.96^{c}$ & $4.22 \pm 0.35^{d}$ \\
\hline B2 & $14.35 \pm 0.57^{f}$ & $3.54 \pm 0.18^{\mathrm{a}}$ & $16.14 \pm 0.57^{e}$ & $460^{b}$ & $7.76 \pm 1.79^{c}$ & $4.11 \pm 0.7^{d}$ \\
\hline \multicolumn{7}{|c|}{$\begin{array}{l}\text { All experiments were carried out in triplicate. Values represent means of three replicated trials } \pm \text { standard deviations. } \\
\text { a-e Values with a different letter within the same column are significantly different }(P<0.05) \text {. } \\
{ }^{*} \text { Abbreviations: } A=1.5 \mathrm{~g} \text { milk fat } 100 \mathrm{~g}^{-1} \text { yoghurt; } \mathrm{B}=2.8 \mathrm{~g} \text { milk fat } 100 \mathrm{~g}^{-1} \text { yoghurt; } 0=\text { no IDFT added; } 1=1.5 \mathrm{~g} \text { IDFT } 100 \mathrm{~g}^{-1} \text { yoghurt; } 2=3.0 \mathrm{~g} \\
\text { IDFT } 100 \mathrm{~g}^{-1} \text { yoghurt. } \\
{ }^{\dagger} \text { Hysteresis loop was the differences in area under the upward and downward curve when plotting shear stress versus shear rate. }\end{array}$} \\
\hline
\end{tabular}

strand as well as strength of each bond. ${ }^{41}$ It also presents the minimum stress required to initiate flow. ${ }^{42}$ The low value of yield stress in yoghurts with IDFT can be explained by the decreased possibility of interactions between protein aggregates due to presence of fibre in continuous phase surrounding the aggregates. These results indicate a structure susceptible to rearrangements and fracture, compared with gels without fibre. Addition of IDFT indicated that yoghurts with both fat contents showed increased structural breakdown due to the difficulty for protein aggregates to rearrange into a homogenous network after shearing, as a consequence of the presence of fibre. Sendra et al. ${ }^{11}$ found that particle size of fibre significantly influences on the rheological properties while Staffolo et al. ${ }^{40}$ showed that the type of fibre is very important, in the same manner.

\section{Textural properties of yoghurts}

An important criterion for quality assessment of yoghurts is their textural properties. Textural properties of yoghurts with different fat and IDFT contents are presented in Table 4.
Our data show significant influence of fat content on the textural properties of yoghurts. It is known that milk fat positively influences the firmness, consistency and reduces whey separation of yoghurts. ${ }^{36}$ The fat globules in homogenised milk interact positively with the protein network and acts as structure promoter. ${ }^{43}$

On the other hand, addition of IDFT did not show significant influence on textural properties of yoghurts made with the same fat content. Fernández-García and McGregor (1997) found that addition of insoluble fibres increased the apparent viscosity of the yoghurts but without significant differences. In general, fibre addition led to gritty texture in all fibre-fortified yoghurts, except in those made with oat fibre. However, rheology and textural properties of yoghurts enriched with fibres depend on the fibre size as well as the concentration. ${ }^{11}$

\section{Sensory evaluation}

Four-way ANOVA applied on overall quality scores showed that only the IDFT and 'fibre content' * 'assessors' interactions were statistically significant $(P<0.01)$. None of the evaluated 


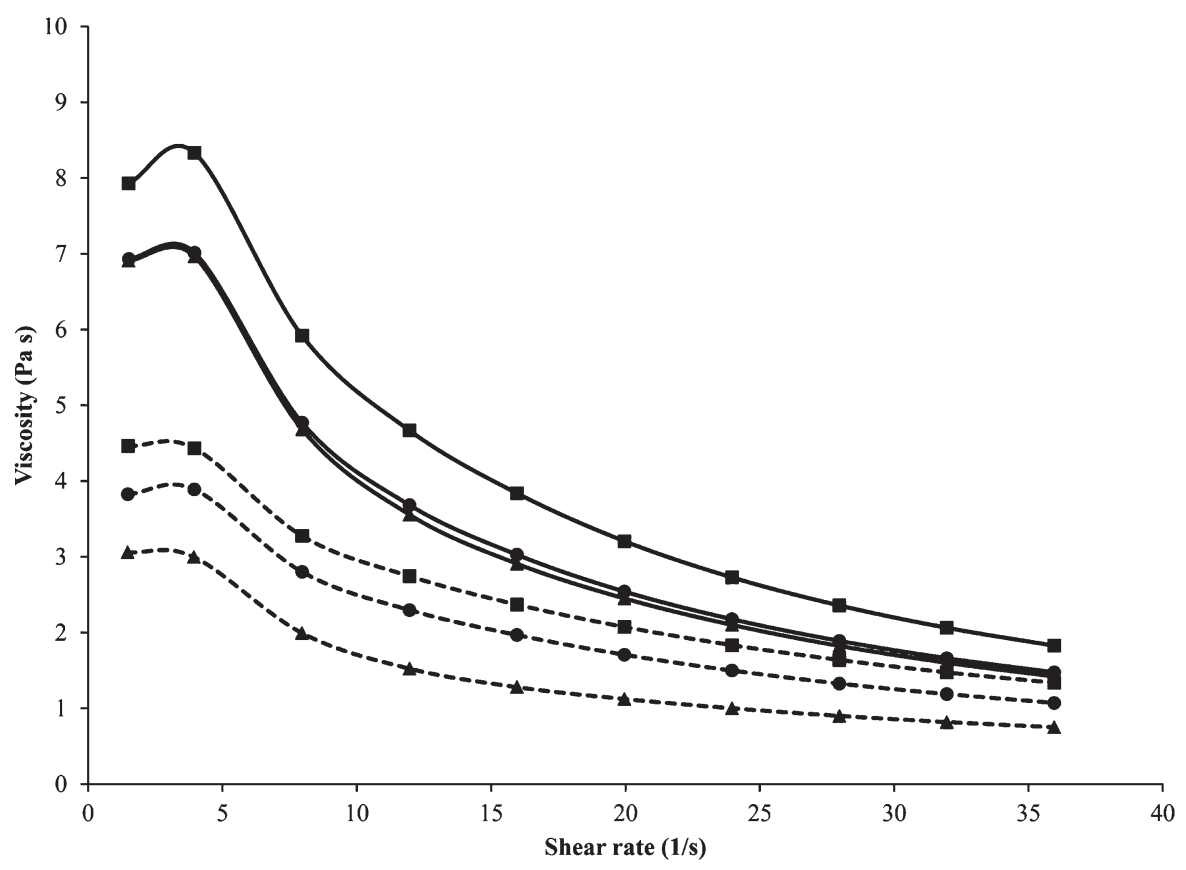

Figure 1. Apparent viscosity of yoghurts as a function of shear rate. All experiments were carried out in triplicate. Values represent means of three replicated trials. Yoghurts made from milk with $1.5 \mathrm{~g}$ milk fat $100 \mathrm{~g}^{-1}$ yoghurt fat and $0,1.5$ and $3 \mathrm{~g}$ IDFT $100 \mathrm{~g}^{-1}$ yoghurt, $(\mathbf{\square}, \boldsymbol{\bullet}, \mathbf{\Lambda}$, dot line, respectively) and- made from milk with $2.8 \mathrm{~g}$ milk fat $100 \mathrm{~g}^{-1}$ yoghurt and $0,1.5$ and $3 \mathrm{~g}$ IDFT $100 \mathrm{~g}^{-1}$ yoghurt, $(\square, \boldsymbol{\bullet}, \mathbf{\Delta}$, solid line, respectively);

characteristics showed a statistically significant difference between samples with both fat contents ('fat content' factor) and the samples at different stages of storage. Also, three-way ANOVA showed that the 'replication' factor was not statistically significant $(P>0.01)$ taking into account each one of the considered attributes. In the other words, milk fat content and the storage time ( 2 or 9 days) did not influence the sensory quality of yoghurt containing IDFT.

Although the sensory profile of yoghurt was perceptibly affected by the presence of IDFT (Table 5), all of the quality scores were within the ranges of 'very good' or 'excellent' quality (i.e. $>3.5$ ). Compared with the control samples ( $\mathrm{AO}$ and $\mathrm{B} 0$ ), the colour of the IDFT fortified samples was described as yellowish - brown and typical for these kind of dairy products that contain whole-grain cereals. The 3\% IDFT samples (A2 and B2) were visibly higher in the colour intensity, as compared with $\mathrm{A} 1$ and $\mathrm{B} 1$ (1.5\% IDFT). Particles of IDFT were visible on the product surface causing the occurrence of mosaic-like appearance with bright and dark colour shades. This appearance was more pronounced in 3\% IDFT samples. The presence of this defect significantly lowered the appearance quality scores of IDFT-fortified samples $(P<0.01)$, as compared with the control samples (Table 5). Based on the response of more than 700 young educated consumers Hoppert et al. ${ }^{44}$ reported that affective acceptance is significantly lower for reduced-sugar yoghurt with visible fibre than for the yoghurt with inulin which is soluble and does not contribute to the colour of yoghurt.

The flavour of yoghurt samples with IDFT was described by the panellists as a flavour which is pleasant and typical for whole-grain cereals dairy products (grainy-like). While the flavour of $1.5 \%$ IDFT samples was described as mild, 3\% IDFT samples were perceived as slightly bitter. This negative flavour note influenced the flavour quality scores of 3\% IDFT samples (the 'very good' quality range) to appear at significantly lower level $(P<0.01)$ compared with $1.5 \%$ IDFT samples (the 'excellent' quality range) (Table 5; 2-day-old samples). In addition, the absence of sugar in yoghurt samples was not described as disadvantage in terms of product quality. For the yoghurts with lower sugar content Hoppert et al. ${ }^{44}$ found that increasing flavour, which could derive from the presence of cereal particles, might be helpful to increase the general acceptance of this kind of reduced-sugar products, concluding that both cereal size and cereal taste are important factors in product formulation because of their impact on general acceptance. Due to perceived grittiness/sandiness, the texture quality was the sensory parameter most negatively affected by the presence of IDFT particles, especially in 3\% IDFT samples. The texture scores of both A2 and B2 samples were significantly lower compared with the rest, but still in the range of 'very good' quality. By fortifying sweetened plain yoghurt with seven types of insoluble dietary fibres from different sources, Fernández-García and McGregor ${ }^{45}$ found that fibre addition, primarily due to the grittiness effect, led to lower overall and texture quality scores. In an another study that included 170 participants, the texture acceptance of probiotic yoghurt fortified with $1 \%$ of passion fruit fibre was at the level of 'neither like nor dislike' at the nine-point hedonic scale. ${ }^{38}$ These results were ascribed not only to the size of fibre particles in yoghurt, but also to the shape of fibres, which had edges like stones, causing the product to have a sandy mouth feel. In contrast, Staffolo et al. ${ }^{40}$ reported that more than $70 \%$ of 25 tested untrained panelists rated the texture acceptance of yoghurt fortified with $1.3 \%$ of wheat fibre with the score of 4 ('like') by using the five-point hedonic scale. They concluded that the addition of $1.3 \%$ dietary fibre to supplement yoghurts appears to be a promising avenue for increased fibre intake, with high consumer acceptability, which is in accordance with our choice of yoghurt enriched with $1.5 \%$ IDFT.

Considering overall sensory quality scores for 2-day-old samples, the $3 \%$ IDFT fortified yoghurt was assessed as the products of a 'very good' quality, while the sensory quality of the yoghurt containing $1.5 \%$ of IDFT was assessed as 'excellent'. 

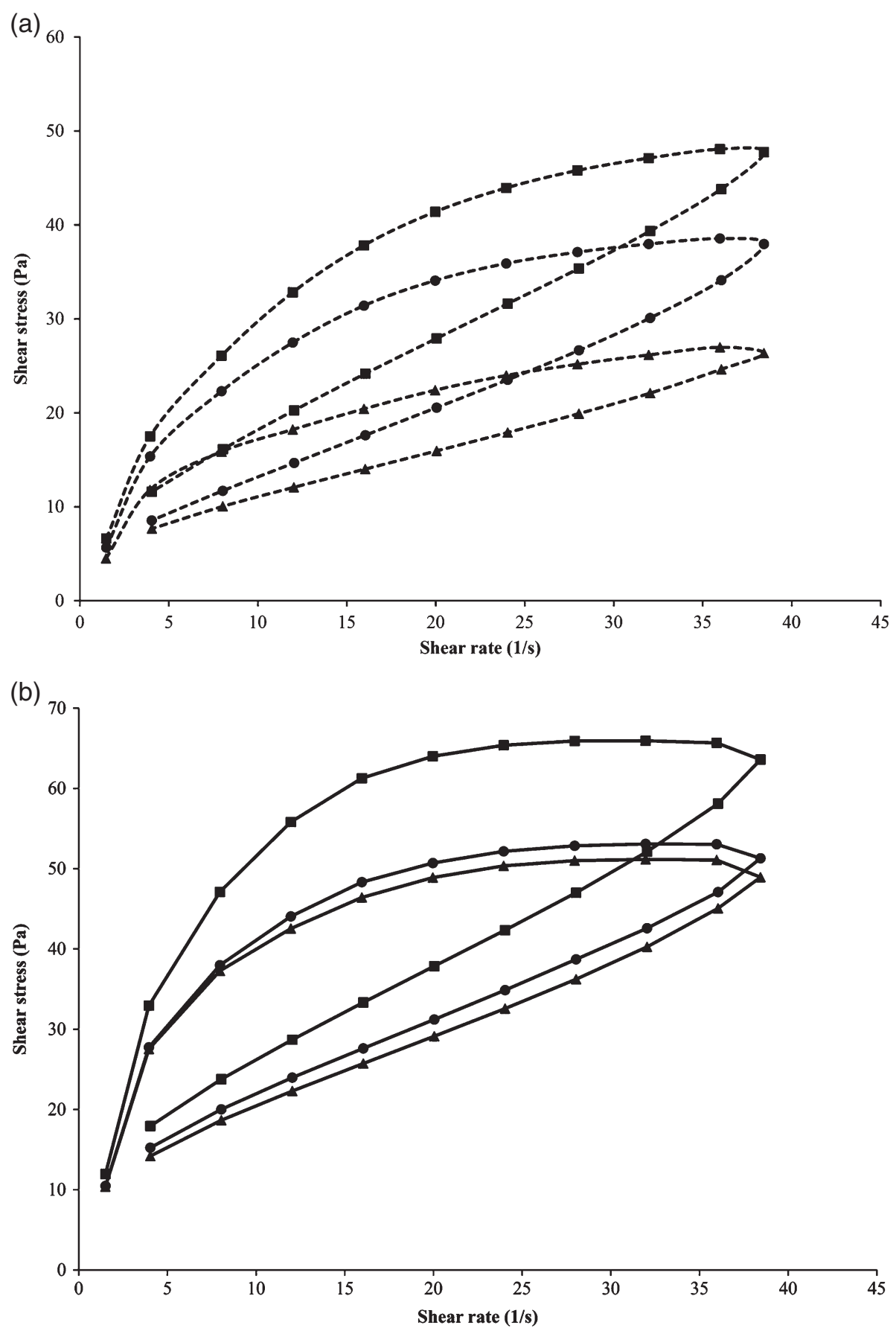

Figure 2. Flow curves of yoghurts made with different fat and triticale fibre contents (a) yoghurts with $1.5 \mathrm{~g}$ milk fat $100 \mathrm{~g}^{-1}$ yoghurt and $0,1.5$ and $3 \mathrm{~g}$ IDFT $100 \mathrm{~g}^{-1}$ yoghurt $\left(\boldsymbol{\square}, \boldsymbol{\bullet}, \mathbf{\Lambda}\right.$, dot line, respectively); and (b) yoghurts with $2.8 \mathrm{~g}$ milk fat $100 \mathrm{~g}^{-1}$ yoghurt and $0,1.5$ and $3 \mathrm{~g}$ IDFT $100 \mathrm{~g}^{-1}$ yoghurt $(\boldsymbol{\square}, \mathbf{\bullet}$, $\Delta$, solid line, respectively).

\section{Antioxidant capacity of yoghurt with IDFT}

In yoghurt with $2.8 \%$ milk fat and $1.5 \%$ IDFT antioxidant capacity was measured and compared with antioxidant capacity of IDFT water extract and yoghurt without IDFT by using the three most commonly used tests (Table 6). All three tests showed that addition of IDFT to yoghurt increase significantly its antioxidant activity. It increases for $8 \%$ according to TPC test and for $9.2 \%$ according to RSA and ABTS tests. Antioxidant activity of yoghurt is known in the literature and depends on the ingredients used ${ }^{46}$ if added before or after inoculation. ${ }^{46,47}$ Different materials such as lentil, ${ }^{48}$ pomegranate peel extracts, ${ }^{47}$ and wine grape pomace ${ }^{49}$ led to increasing antioxidant activity of yoghurt. This work gives a first detailed analysis of the antioxidant potential of IDFT, which is proved by the increased antioxidant activity in the final food product.

\section{CONCLUSIONS}

Yoghurt enriched with innovative IDFT has been confirmed as a prospective functional food. Addition of IDFT in yoghurt enhanced antioxidant activity by $8-9 \%$ and significantly influenced the 
Table 4. Textural properties of yoghurt with different fat and triticale insoluble dietary fibre content

Yoghurt

sample

Firmness (g)

Consistency (g s)

Cohesiveness (g)

Index of viscosity (g s)

$\mathrm{AO}$

$38.30 \pm 1.53^{\mathrm{a}}$

$995.26 \pm 45.99^{a}$

$941.86 \pm 131.57^{\mathrm{a}}$

$-47.19 \pm 4.13^{\mathrm{a}}$

$-120.03 \pm 11.02^{\mathrm{a}}$

$36.24 \pm 4.63^{\mathrm{a}}$

$961.27 \pm 108.36^{a}$

$-91.92 \pm 14.98^{\mathrm{a}}$

$39.44 \pm 3.90^{\mathrm{a}}$

$-37.38 \pm 4.98^{\mathrm{a}}$

$-86.19 \pm 10.70^{\mathrm{a}}$

$56.02 \pm 2.76^{\mathrm{b}}$

$-35.32 \pm 3.49^{a}$

$-176.18 \pm 15.41^{b}$

$62.03 \pm 5.68^{b}$

$1483.37 \pm 70.15^{\mathrm{b}}$

$-71.07 \pm 6.47^{b}$

$-185.05 \pm 19.30^{b}$

B1

$60.19 \pm 8.14^{b}$

$1625.23 \pm 155.22^{\mathrm{b}}$

$-75.73 \pm 8.16^{b}$

$-178.33 \pm 26.17^{b}$

All experiments were carried out in triplicate. Values represent means of three replicated trials \pm standard deviations.

${ }^{a}$ Values with different letters within the same column are significantly different $(P<0.05)$.

*Abbreviations: $A=1.5 \mathrm{~g}$ milk fat $100 \mathrm{~g}^{-1}$ yoghurt; $\mathrm{B}=2.8 \mathrm{~g}$ milk fat $100 \mathrm{~g}^{-1}$ yoghurt; $0=$ no IDFT added; $1=1.5 \mathrm{~g}$ IDFT $100 \mathrm{~g}^{-1}$ yoghurt; $2=3.0 \mathrm{~g}$

IDFT $100 \mathrm{~g}^{-1}$ yoghurt.

Table 5. Sensory quality scores for yoghurts fortified with triticale insoluble dietary fibre (IDFT)

\begin{tabular}{|c|c|c|c|c|c|}
\hline Yoghurt type* & Overall quality & Appearance & Odour & Flavour & Texture \\
\hline \multicolumn{6}{|c|}{ 2-day-old products } \\
\hline AO & $4.6 \pm 0.3^{b}$ & $4.8 \pm 0.4^{b}$ & $4.7 \pm 0.4^{\mathrm{a}}$ & $4.6 \pm 0.4^{c}$ & $4.6 \pm 0.4^{b}$ \\
\hline A1 & $4.5 \pm 0.4^{b}$ & $4.6 \pm 0.4^{\mathrm{a}, \mathrm{b}}$ & $4.8 \pm 0.3^{a}$ & $4.6 \pm 0.5^{b, c}$ & $4.4 \pm 0.5^{b}$ \\
\hline $\mathrm{A} 2$ & $4.1 \pm 0.5^{a}$ & $4.3 \pm 0.5^{a}$ & $4.6 \pm 0.5^{\mathrm{a}}$ & $4.1 \pm 0.6^{a}$ & $3.9 \pm 0.7^{a}$ \\
\hline B0 & $4.8 \pm 0.2^{b}$ & $4.7 \pm 0.4^{b}$ & $4.8 \pm 0.3^{a}$ & $4.8 \pm 0.3^{c}$ & $4.7 \pm 0.3^{b}$ \\
\hline B1 & $4.6 \pm 0.4^{b}$ & $4.6 \pm 0.4^{\mathrm{a}, \mathrm{b}}$ & $4.8 \pm 0.4^{\mathrm{a}}$ & $4.6 \pm 0.5^{c}$ & $4.5 \pm 0.4^{b}$ \\
\hline B2 & $4.2 \pm 0.5^{\mathrm{a}}$ & $4.4 \pm 0.5^{\mathrm{a}}$ & $4.6 \pm 0.5^{a}$ & $4.2 \pm 0.6^{a, b}$ & $4.0 \pm 0.6^{a}$ \\
\hline \multicolumn{6}{|c|}{ 9-day-old products } \\
\hline A0 & $4.5 \pm 0.5^{9}$ & $4.8 \pm 0.4^{g}$ & $4.5 \pm 0.7^{e, f}$ & $4.4 \pm 0.7^{f}$ & $4.6 \pm 0.6^{h}$ \\
\hline A1 & $4.3 \pm 0.5^{f, g}$ & $4.4 \pm 0.5^{e, f}$ & $4.5 \pm 0.5^{e, f}$ & $4.3 \pm 0.6^{\mathrm{e}, \mathrm{f}}$ & $4.2 \pm 0.7^{f, g}$ \\
\hline A2 & $3.9 \pm 0.6^{\mathrm{e}}$ & $4.3 \pm 0.5^{\mathrm{e}}$ & $4.3 \pm 0.7^{\mathrm{e}}$ & $3.8 \pm 0.8^{e}$ & $3.7 \pm 0.7^{e}$ \\
\hline BO & $4.5 \pm 0.6^{f, g}$ & $4.7 \pm 0.4^{f, g}$ & $4.5 \pm 0.6^{e, f}$ & $4.2 \pm 1.0^{\text {e.f }}$ & $4.7 \pm 0.4^{h}$ \\
\hline B1 & $4.5 \pm 0.4^{g}$ & $4.5 \pm 0.5^{e, f, g}$ & $4.6 \pm 0.6^{f}$ & $4.4 \pm 0.5^{f}$ & $4.5 \pm 0.5^{g, h}$ \\
\hline B2 & $4.1 \pm 0.6^{\mathrm{e}, \mathrm{f}}$ & $4.4 \pm 0.5^{e}$ & $4.5 \pm 0.6^{e, f}$ & $4.1 \pm 0.7^{e, f}$ & $3.9 \pm 0.7^{e, f}$ \\
\hline
\end{tabular}

Table 6. Antioxidant activity of yoghurt enrichment with IDFT

\begin{tabular}{|c|c|c|}
\hline Antioxidant assay & Yoghurt & $\begin{array}{l}\text { Yoghurt enrichment } \\
\text { with IDFT (1.5\%) }\end{array}$ \\
\hline ABTS ( $\mu$ mol vit $\mathrm{C}^{-1}$ sample) & 308.44 & 339.6 \\
\hline RSA (\%) & 29.68 & 32.42 \\
\hline TPC (mg GAE g $\left.{ }^{-1}\right)$ & 2.68 & 2.92 \\
\hline
\end{tabular}

syneresis level, its apparent viscosity, yield stress and thixotropic behaviour, while it did not show significant influence on the textural properties of yoghurts. The overall sensory quality scores indicated that yoghurt enriched with IDFT was recognised as 'excellent', which is critical to the food market. Potential commercialisation of this fibre as a novel functional component of dairy products is possible which was proven by results of its hydration capacity (higher than similar fibres), good chemical composition (rich in essential microelements) and high antioxidant activity. IDFT contribute to final food product with negligible calorific value; enhanced antioxidant activity and the total content of essential elements, with no phytates. Application of the innovative IDFT in other dairy products could offer a better insight into its optimal application. To compensate for specificities of other types of food, additional research is needed to determine if similar results would be derived within other food products.

\section{ACKNOWLEDGEMENTS}

This study was supported by grants from the Serbian Ministry of Education, Science and Technological Development (projects No. ON 172048 and 451-03-2082-Tip 1/75).

\section{REFERENCES}

1 Europe ILSI-I, Scientific concepts of functional foods in Europe. Consensus document. Br J Nutr 81:S1-S27 (1999).

2 Eastwood MA, Robertson JA, Brydon WG and MacDonald D, Measurement of water-holding properties of fibre and their faecal bulking ability in man. Br J Nutr 50:539-547 (1983).

3 Slavin JL, Dietary fiber and body weight. Nutrition 21:411-418 (2005).

4 Mazza $\mathrm{G}$ and Kay CD, Bioactivity, Absorption, and metabolism of anthocyanins, in Recent Advances in Polyphenol Research, Wiley-Blackwell, Hoboken, NJ, pp. 228-262 (2009). 
5 Dojnov B, Vujčić Z, Margetić A and Vujčić M, Process for the production of insoluble, low-calorie, non-allergenic dietary fiber from triticale. Republic of Serbia Patent 2016/3,8 (2016).

6 Agil R and Hosseinian F, Dual functionality of triticale as a novel dietary source of prebiotics with antioxidant activity in fermented dairy products. Plant Foods Hum Nutr 67:88-93 (2012).

7 Hosseinian FS and Mazza G, Triticale bran and straw: Potential new sources of phenolic acids, proanthocyanidins, and lignans. J Funct Foods 1:57-64 (2009).

8 McGoverin CM, Snyders F, Muller N, Botes W, Fox G and Manley M, A review of triticale uses and the effect of growth environment on grain quality. J Sci Food Agric 91:1155-1165 (2011).

9 Salmon DF, Mergoum M and Gómez Macpherson H, Triticale production and management, in Triticale Improvement and Production, ed. by Mergoum M and Gomez-Macpherson H. FAO, Rome, pp. 27-37 (2004).

10 Pena RJ, Food uses of triticale, in Triticale Improvement and Production, ed. by Mergoum M and Gomez-Macpherson H. FAO, Rome, pp. 37-49 (2004).

11 Sendra E, Kuri V, Fernández-López J, Sayas-Barberá E, Navarro C and Pérez-Alvarez JA, Viscoelastic properties of orange fiber enriched yogurt as a function of fiber dose, size and thermal treatment. LWT - Food Sci Technol 43:708-714 (2010).

12 Fernandez-Garcia E and McGregor JU, Fortification of sweetened plain yogurt with insoluble dietary fiber. $Z$ Lebensm Unters Forsch A 204: 433-437 (1997).

13 Lobato-Calleros C, Ramírez-Santiago C, Vernon-Carter EJ and Alvarez-Ramirez J, Impact of native and chemically modified starches addition as fat replacers in the viscoelasticity of reduced-fat stirred yogurt. J Food Eng 131:110-115 (2014).

14 Thebaudin JY, Lefebvre AC, Harrington M and Bourgeois CM, Dietary fibres: Nutritional and technological interest. Trends Food Sci Technol 8:41-48 (1997).

15 Pejin D, Mojović LJ, Vučurović V, Pejin J, Denčić S and Rakin M, Fermentation of wheat and triticale hydrolysates: A comparative study. Fuel 88:1625-1628 (2009).

16 Dojnov B, Grujić M, Perčević B and Vujčić Z, Enhancement of amylase production using carbohydrates mixtures from triticale in Aspergillus sp. J Serb Chem Soc 80:1279-1288 (2015).

17 Robertson JA, de Monredon FD, Dysseler P, Guillon F, Amado R and Thibault J-F, Hydration properties of dietary fibre and resistant starch: a European collaborative study. LWT - Food Sci Technol 33:72-79 (2000).

18 Grigelmo-Miguel N, Gorinstein S and Martin-Belloso O, Characterisation of peach dietary fibre concentrate as a food ingredient. Food Chem 65:175-181 (1999).

19 Bradford M, A rapid and sensitive method for the quantitation of microgram quantities of protein utilizing the principle of protein-dye binding. Anal Biochem 72:248-254 (1976).

20 Bernfeld P, Amylases, $\alpha$ and $\beta$, in Methods in Enzymology, ed. by De Murray P. Deutcher Academic Press, San Diego CA, pp. 149-158 (1955).

21 Briggs DE, Modification of the Sandstedt, Kneen and Blish assay of $\alpha$-amylase. J Ind Brewing 67:427 (1961).

22 Bae HD, Yanke LJ, Cheng KJ and Selinger LB, A novel staining method for detecting phytase activity. J Microbiol Meth 39:17-22 (1999).

23 Agbor AG, Vinson AJ and Donnelly EP, Folin Ciocalteau reagent for polyphenolic assay. Int J Food Sci Nutr Diet 3:147-156 (2014).

24 Miocinovic J, Miloradovic Z, Josipovic M, Nedeljkovic A, Radovanovic M and Pudja P, Rheological and textural properties of goat and cow milk set type yoghurts. Int Dairy J 58:43-45 (2016).

25 Guggisberg D, Cuthbert-Steven J, Piccinali P, Bütikofer $U$ and Eberhard $\mathrm{P}$, Rheological, microstructural and sensory characterization of low-fat and whole milk set yoghurt as influenced by inulin addition. Int Dairy $J$ 19:107-115 (2009).

26 Ramirez-Santiago C, Ramos-Solis L, Lobato-Calleros C, Peña-Valdivia C, Vernon-Carter EJ and Alvarez-Ramírez J, Enrichment of stirred yogurt with soluble dietary fiber from Pachyrhizus erosus L. Urban: Effect on syneresis, microstructure and rheological properties. J Food Eng 101:229-235 (2010).
27 Brand-Williams W, Cuvelier ME and Berset C, Use of a free radical method to evaluate antioxidant activity Lebensm-Wiss u-Technol 28:25-30 (1995).

28 Raman M, Nilsson U, Skog K, Lawther M, Nair B and Nyman M, Physicochemical characterisation of dietary fibre components and their ability to bind some process-induced mutagenic heterocyclic amines, Trp-P-1, Trp-P-2, A $\alpha$ C and MeA $\alpha$ C. Food Chem 138:2219-2224 (2013).

29 Gupta RK, Gangoliya SS and Singh NK, Reduction of phytic acid and enhancement of bioavailable micronutrients in food grains. J Food Sci Technol 52:676-684 (2015).

30 Benítez V, Mollá E, Martín-Cabrejas MA, Aguilera Y and Esteban RM, Physicochemical properties and in vitro antidiabetic potential of fibre concentrates from onion by-products. J Funct Foods 36:34-42 (2017).

31 Lorenz K, Reuter FW and Sizer C, The mineral composition of triticales and triticale milling fractions by $\mathrm{X}$-ray fluorescence and atomic absorption. Cereal Chem 51:376-382 (1974).

32 Zhu K, Huang S, Peng W, Qian H and Zhou H, Effect of ultrafine grinding on hydration and antioxidant properties of wheat bran dietary fiber. Food Res Int 43:943-948 (2010).

33 Rodríguez R, Jiménez A, Fernández-Bolaños J, Guillén R and Heredia A, Dietary fibre from vegetable products as source of functional ingredients. Trends Food Sci Technol 17:3-15 (2006).

34 Saura-Calixto F, Antioxidant dietary fiber product: a new concept and a potential food ingredient. J Agric Food Chem 46:4303-4306 (1998).

35 Buranov AU and Mazza G, Lignin in straw of herbaceous crops. Ind Crop Prod 28:237-259 (2008).

36 Tamime AY and Robinson RK, Yoghurt Science and Technology. Woodhead Publishing, Cambridge, UK (2007).

37 Zare F, Boye Jl, Orsat V, Champagne C and Simpson BK, Microbial, physical and sensory properties of yogurt supplemented with lentil flour. Food Res Int 44:2482-2488 (2011).

38 Espírito-Santo AP, Lagazzo A, Sousa ALOP, Perego P, Converti A and Oliveira MN, Rheology, spontaneous whey separation, microstructure and sensorial characteristics of probiotic yoghurts enriched with passion fruit fiber. Food Res Int 50:224-231 (2013).

39 Lee WJ and Lucey JA, Formation and physical properties of yogurt. Asian Austral J Anim Sci 23:1127-1136 (2010).

40 Staffolo MD, Bertola N, Martino M and Bevilacqua YA, Influence of dietary fiber addition on sensory and rheological properties of yogurt. Int Dairy J 14:263-268 (2004).

41 van Vliet T, van Dijk HJM, Zoon P and Walstra P, Relation between syneresis and rheological properties of particle gels. Colloid Polym Sci 269:620-627 (1991).

42 Steffe JF, Rheological Methods in Food Process Engineering. Freeman Press, East Lansing, MI (1996).

43 Sodini I and Tong PS, Milk and milk-based dairy ingredients, in Manufacturing Yogurt and Fermented Milks, ed. by Chandan RC. Blackwell Publishing Asia, Carlton, Australia, pp. 167-179 (2006).

44 Hoppert K, Zahn S, Jänecke L, Mai R, Hoffmann S and Rohm H, Consumer acceptance of regular and reduced-sugar yogurt enriched with different types of dietary fiber. Int Dairy J 28:1 -7 (2013).

45 Fernández-García E and McGregor JU, Fortification of sweetened plain yogurt with insoluble dietary fiber. Z Lebensm Unters Forsch 204: 433-437 (1997).

46 Sanlıdere Aloğlu H and Öner Z, Determination of antioxidant activity of bioactive peptide fractions obtained from yogurt. J Dairy Sci 94:5305-5314 (2011).

47 El-Said MM, Haggag HF, Fakhr El-Din HM, Gad AS and Farahat AM, Antioxidant activities and physical properties of stirred yoghurt fortified with pomegranate peel extracts. Ann Agric Sci 59:207-212 (2014).

48 Agil R, Gaget A, Gliwa J, Avis TJ, Willmore WG and Hosseinian F, Lentils enhance probiotic growth in yogurt and provide added benefit of antioxidant protection. LWT - Food Sci Technol 50:45-49 (2013).

49 Tseng $A$ and Zhao $Y$, Wine grape pomace as antioxidant dietary fibre for enhancing nutritional value and improving storability of yogurt and salad dressing. Food Chem 138:356-365 (2013). 